\title{
Study on the Design of Campus Network-based Personalized English Teaching Platform
}

\author{
https://doi.org/10.3991/ijet.v13i04.8475 \\ Hongmei Wang $\left({ }^{\square}\right)$ \\ Jilin Institute of Chemical Technology, Jilin 132022, China \\ 3146808@qq.com
}

\begin{abstract}
College English teaching is in urgent need of a platform which may improve students' initiative in English learning, raise learning interest and enhance English teaching management, in order to improve students' English level and facilitate the teacher's English teaching management. The popularity of campus network facilities in various universities provides hardware support for the establishment of a personalized English teaching platform based on campus network. The study is aimed at designing a personalized English teaching platform based on campus network, which takes VBSCRIPT as programming language and SQL Server as database software of the platform, completing the interactive processing of the data based on the data structure of client computer/server $(\mathrm{B} / \mathrm{S})$. First, the paper introduces the relevant teaching and education theories, laying theoretical and technical basis for the design of personalized English teaching platform in combination with the computer technology used in the design of the platform. The combination of questionnaire and analytic study is used in the design of the system from various aspects, and makes the design of the platform come true. At last, the testing of the system verifies that the system meets the relevant functional requirement. The platform would provide an open environment for English learning and stimulating the guidance of teachers and is of great significance to improve the level of college English teaching.
\end{abstract}

Keywords-campus network; personalized teaching platform; VBSCRIPT;

SQL server; B/S framework

\section{Introduction}

English, as the most widely used international language, has its self-evident importance. The foreign language proficiency of college students has a direct impact on their employment after graduation and study abroad. In recent years, college English learning has been weakened by lack of effective motivation and English learning environment, so that college English education and learning have been stagnant in ordinary colleges and universities [1]. Examination-oriented education and coping learning are becoming more and more serious in college English teaching. The study and design of a personalized English teaching platform based on campus network is the effective way to address the issue and the platform may not only stimulate stu- 
dents' initiative and interest in English learning but also improve the management level of English teaching [2].

With the rapid popularization of computer networks, the construction of campus networks in universities has begun to take shape. Most colleges and universities have their own independent campus networks with a set of independent campus network management system [3]. At the same time, the application effect of network teaching and computer aided teaching has been verified. Therefore, it is worthwhile to use the campus networks to provide students with an English learning platform and thus help college English teaching. The paper first introduces theories of the personalized learning and constructivist learning, with a focus on the major role of leaners and guiding role of teachers in learning [4]; then uses VBSCRIPT as the programming language of the platform, on which the data interaction is realized between Web browser side, WEB server and background SQL data based on the data architecture of $\mathrm{B} / \mathrm{S}$, and adopts SQL database technology, which may facilitate the diversity of English teaching contents, teachers and students' visits and the overall management of English teaching. In addition, the paper analyzes the requirements of teaching platform, system framework and system database, and improve the functional requirements of the system with questionnaire and research analyses [5]. Finally, a personalized English teaching platform based on campus network is designed: students can learn and master their own learning dynamics and English scores according to their English proficiency; teachers get a full understanding of the students' learning status and play a guiding role. The design of the platform would promote the development and application of college English network teaching, and provide a teaching platform, which meets the needs of both teachers and students in college English learning.

\section{Introduction to Education and Teaching Theories and Computer Technology}

\subsection{Education and teaching theories}

Personalized learning. Related scholars believe that personalized learning is mainly divided into such five perspectives as users, system, process, output and strategies. Personalized learning refers to that students choose their own learning content and learning path based on their own characteristics and needs. Personalized learning is not an isolated self-learning, but also includes the improvement of the personality development through cooperative learning [6]. The system for personalized learning should have the learning materials in the form of information customization, with which learners can customize the learning contents according to their own needs; if the system lacks relevant content, learners can search the relevant resources through the Internet and customize the required contents in the personal learning system, creating an open and independent personalized learning environment [7].

Constructivist learning theory. Constructivist learning theory stresses the learner-centered and believes that learning is the process of learners' active construction of their knowledge and the process of cognition and reconstruction of the original 
knowledge base. Learning involves not only passive teaching, but also active knowledge acquisition. Of course, constructivist learning theory does not ignore the guiding role of teachers [8]. In constructivist learning theory, the requirements for students and teachers are as follows:

Students should: (1) learn to use exploration and discovery; (2) actively collect and analyze data and information, make higher assumptions about learning contents and try to verify them; (3) build the relationship between "connection" and thinking, and improve the efficiency and quality in the learning process.

Teachers should play the role of facilitator and facilitator from the following aspects: (1) stimulate learning interest and form learning motivation; (2) create a learning situation, give relevant hints for learning, and help learners understand the meaning of the knowledge; (3) organize group discussion and exchange, and guide the process of collaborative learning.

\subsection{Computer technologies}

VBSCRIPT programing language. VBSCRIPT, abbreviated as VBS, is a scripting language developed by Microsoft and a simple version of Visual Basic [9]. VBS is Microsoft's lightweight interpretation language and also a default language for dynamic Asp web programming, and together with Asp and ADO objects, users can master Asp dynamic web development technology.

VB Script is usually applied in following three practical aspects: 1 . Windows operation, mainly used to perform automated, completed and repetitive operating system tasks; 2 . Web browser, the client's web browser is directed by the web VBS to realize dynamic HTML; 3 . Web server, the program code for VBS is directly embedded into the HTML page with ASP as the end. The program in the ASP page transforms the execution structure into the HTML to be used by the users in the web browser [10]. In this way, the server puts the corresponding results into the HTML web page. VBS does not pose a major burden on server load and is easier to control. Used in most Windows operators, it is a transfer to conveniently implement other programs, including office programs.

SQL Server database. In this paper, SQL server database is used to conduct data management of personalized English grammar test and diagnosis database data, and is a database of distribution. Structured Query Language - Structured Query Language, or SQL Language, is a database query and programming language for accessing queries, updating, and managing relational database systems [11].

Four parts of SQL and their functions are as shown in Table 1.

Table 1. The main function of SQL 4 parts

\begin{tabular}{|l|l|}
\hline \multicolumn{1}{|c|}{ Compositions } & \multicolumn{1}{|c|}{ Function } \\
\hline Data definition & $\begin{array}{l}\text { Mainly to define the logical structure of the database, including } \\
\text { Database, table, view and index four parts }\end{array}$ \\
\hline Data manipulation & To include data query and update two categories of operations, \\
\hline Data control & Control of user access to data \\
\hline Application regulations & Specifies that the SQL statement is used in the program of the host language \\
\hline
\end{tabular}


B/S framework. B/S framework (Browser/Server model) is a pattern of network architecture after the emergence of the WEB, which is the most important application of the clients. The model unifies the clients, centralizes the core of the system function to the server, and simplify the development, maintenance and use of the system [12]. With just a browser stalled on the client such as Netscape Navigator or Internet Explorer, such databases as SQL Server, Oracle, MYSQL and ACCESS are installed on the server. The browser interacts with the database through the Web Server with the data structure framework as shown in Figure 1:

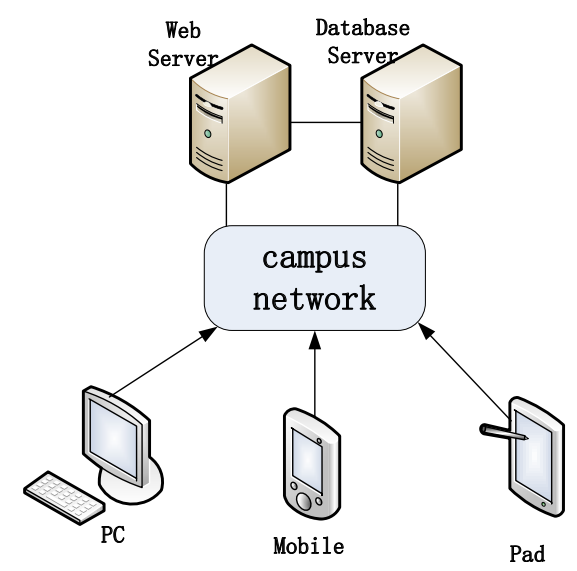

Fig. 1. The Data framework of $B / S$ structure

Based on the $\mathrm{B} / \mathrm{S}$ framework, this paper takes campus network as intermediate to mainly implement the design of a personalized English teaching platform on computer.

\section{System Requirement Analysis}

\subsection{Questionnaire of system requirements}

The personalized English teaching platform, aimed at improving students' autonomous learning ability, is a reform of the English teaching process. The needs of students and teachers should be the primary goal of system. The system should grasp the students' interest in English, purposes and main ways of learning; and subdivide the requirements for teachers in various aspects [13]. In this study, a questionnaire survey is conducted to master the system requirements of students and teachers on the personalized English teaching platform.

Designing the questionnaire. Due to the differences in requirements between teachers and students, the questionnaire is divided into two categories: teacher questionnaire and student questionnaire. The questionnaire involves with the aspects of platform openness, functional interface design and practice test design, which corre- 
spond to modules such as teaching strategy, function module, question setting and interface setting.

Sampling. The subjects of this paper are mainly non-English majors, as well as relevant English teachers. 300 questionnaires are distributed to college students with 29 valid questionnaires collected; 20 questionnaires are distributed to teachers with 20 valid questionnaires collected.

\section{Results of questionnaires.}

Investigation on system openness. 78\% of the students surveyed said they had no access to online English teaching platforms. For the Question "Why choose the English teaching platform", $26 \%$ of the students for consolidating the content learned in the classroom, $23 \%$ of the students for preview before class, $22 \%$ of the students for expanding knowledge and $29 \%$ of the students for evaluating learning effect. In 20 questionnaires for teachers, $90 \%$ of the teachers think that the traditional classroom cannot be replaced by the online English teaching model. $96 \%$ of teachers are satisfied with the open mode of online learning platform and express that they don't want to intervene the learning progress of students in the online English learning [14]. Therefore, students and teachers expect to have an open network environment to provide them with an autonomous learning platform.

Realization of functional interface design. The modules such as unit test, score statistics, textbook knowledge development and English grammar explanation reflect the students' learning process at the same time. And practice and practice management are the functional interface that the teachers are more concerned about [15].

Practice and test reminders. From the evaluation statistics on the setting of questions by students as shown in Table 3 , the multiple choice question is the most popular question of the students surveyed, and questions to be manually filled in the blank is the most unpopular type.

Table 2. The student questionnaire survey results table

\begin{tabular}{|l|c|c|c|c|c|c|}
\hline Attitude/Question & $\begin{array}{c}\text { Extension } \\
\text { knowledge }\end{array}$ & $\begin{array}{c}\text { Study } \\
\text { situation } \\
\text { query }\end{array}$ & $\begin{array}{c}\text { Unit test } \\
\text { and score } \\
\text { summary }\end{array}$ & $\begin{array}{c}\text { Online com- } \\
\text { munication }\end{array}$ & $\begin{array}{c}\text { Grammar } \\
\text { special } \\
\text { practice }\end{array}$ & $\begin{array}{c}\text { Platform com- } \\
\text { munication }\end{array}$ \\
Frequently used & $92 \%$ & $60 \%$ & $98 \%$ & $58 \%$ & $75 \%$ & $61 \%$ \\
\hline Do not like to use & $1 \%$ & $0 \%$ & $4 \%$ & $5 \%$ & $2 \%$ & $0 \%$ \\
Useful & $75 \%$ & $95 \%$ & $98 \%$ & $52 \%$ & $88 \%$ & $90 \%$ \\
\hline Useless & $0 \%$ & $0 \%$ & $0 \%$ & $2 \%$ & $10 \%$ & $1 \%$ \\
\hline
\end{tabular}

Table 3. The evaluation form of the student to questions

\begin{tabular}{|l|c|c|c|c|}
\hline \multicolumn{1}{|c|}{ Attitude/Question } & $\begin{array}{c}\text { English } \\
\text { writing }\end{array}$ & Fill-in-the-blank & $\begin{array}{c}\text { True or } \\
\text { False }\end{array}$ & Choice question \\
\hline The questions you like & 42 & 2 & 78 & 95 \\
\hline The questions you don't like & 50 & 85 & 0 & 0 \\
\hline
\end{tabular}




\subsection{Analysis of functional and non-functional requirements of the platform}

\section{Functional requirements of the platform.}

1. Teaching resources. Providing students with access to English teaching resources and automatic download drawings for type exercises, special exercises, audio and video learning and the registered users may revise their own teaching resources [16].

2. Teaching and learning. Students can independently browse the course information and related knowledge content after entering the network teaching platform.

3. Exercises and test management and analysis. Exercises are the key to improving students' English proficiency, allowing students to train on a system-by-cycle basis. At the same time, the platform should have the inquiries of results, result statistics, results exporting and other functions.

4. Interactive and exchange block. The system should be able to answer questions raise by students in the learning process. Questions in the learning process can be solved through the communication between students and the communication between students and teachers.

Non-functional requirements of the platform. Non-functional requirements include reliability, security, easy to use, interoperability, maintainability and extensibility.

1. Platform performance. For the personalized English teaching platform, the performance indexes mainly include system response time and system load. This design meets the online learning of at least 200 English students at the same time.

2. Security and reliability of the platform. The system has the login module, and the unauthorized users cannot access the system question bank. The features of the campus network may also prevent malicious attacks from outside networks.

3. Maintainability of the platform. The maintenance can be conducted directly on the server side, directly changing the defects of the module on the server side.

4. Environment requirements for platform development: Operating system: window XP, Window 7, 8, 10 Server; Database: SQ Server, 2003; Development tools: Edit plus; Development language: VBSCRIPT; Web server: IIS 6.0. B/S model: Win7+IIS+SQL Server, Client: IE6.0 and above browser.

\subsection{Framework requirements of system functional modules}

From the overall functional framework of personalized English teaching platform based on campus network as shown in Figure 2, the platform focuses on meeting the needs of students, giving consideration of meeting the needs of teachers and administrators, to meet personalized learning and constructivism learning theory. 


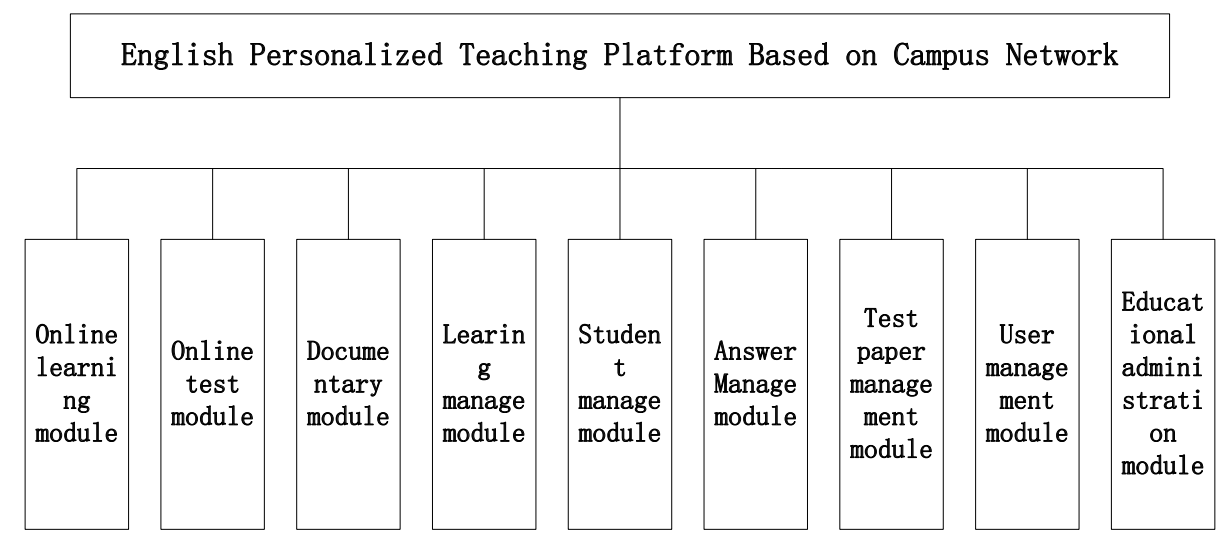

Fig. 2. The overall structure of the teaching platform

There are different types of sub-function modules under the system's main function module. There are learning records, wrong records, personal management and other sub-modules under file management modules; the student management module includes approve students, inquire students, cancel students, edit students, and review students; test management module has three sub-modules such as add questions, delete questions, and edit questions.

\subsection{Analysis of database requirements}

Autonomous learning is the core of the platform, and the database design is related to system performance and data integrity. The data table design for database is the basic unit of SQL sever data storage, and data tables are used to record and save data, which are independent but related to each other in the system. The basic information of teachers, students and administrators is stored in the form of data tables as shown in Table 4 for teachers.

Table 4. The teacher basic information table

\begin{tabular}{|c|c|c|c|c|}
\hline Serial number & Column name & Data Type & Chinese column name & Length \\
\hline 1 & account_id & char & teacher number & 4 \\
\hline 2 & name & varchar & user name & 20 \\
\hline 3 & password & varchar & password & 20 \\
\hline 4 & id & int & code & 4 \\
\hline
\end{tabular}

Not only the types of users, but also different types of questions such as multiple choice questions, structural questions, translation questions and basic exercises have their different types of data storage models. 


\subsection{Detailed explanation of the function of student learning modules}

In order to further explain the detailed functions of English learning on the system platform, the student's English learning business process is illustrated in detail in Figure 3.

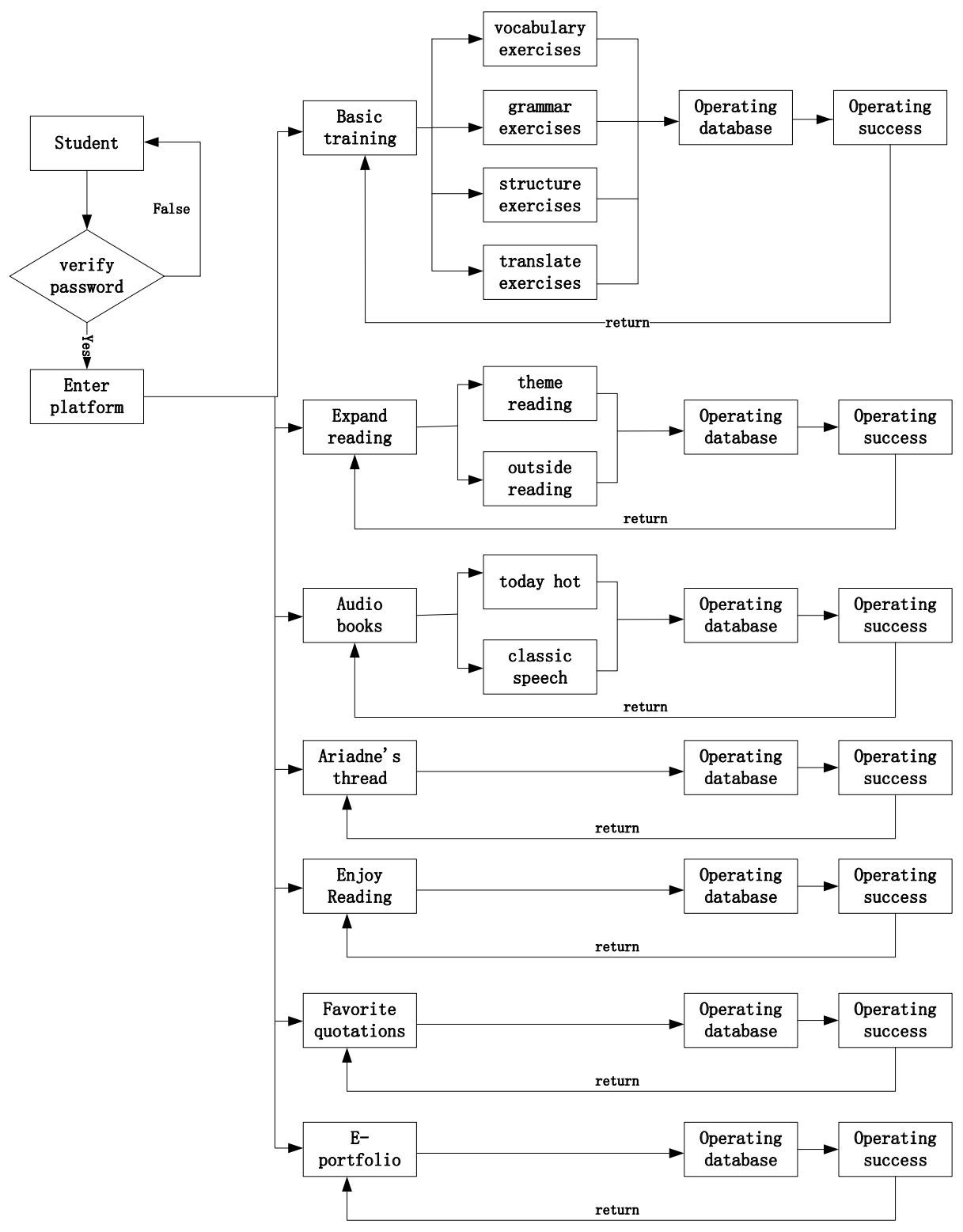

Fig. 3. The students learning business flow chart 


\section{Realization of Personalized English Teaching Platform Based on Campus Network}

According to the design idea required by the system, the programming is completed by using SQL language and VBSCRIPT language, and the system interface is tested accordingly.

\subsection{System interface}

Firstly, the system login interface is designed mainly to meet functions of the user system login, password recovery, and new user registration. The login interface of the computer learning system for personalized detection and diagnosis of college English grammar is shown in Figure 4.

Figure 5 shows the main page of student learning, whose interface function is consistent with system requirement analysis. The screenshot interface is the page that students check the definition and examples of English apposition in the labyrinth module.

The interface of the system also includes an administrator interface and a teacher interface, which is no longer described here. After the design of each interface of the system, the function of the system needs to be tested.

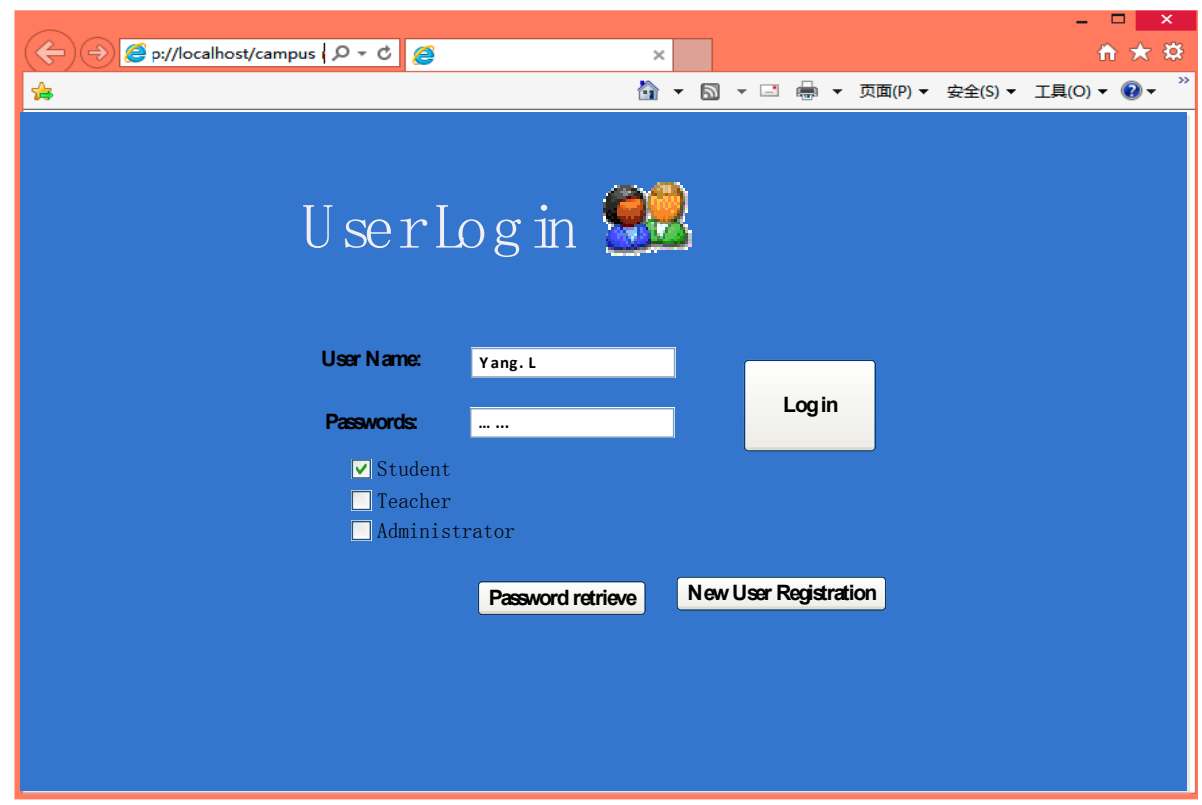

Fig. 4. system log in interface 


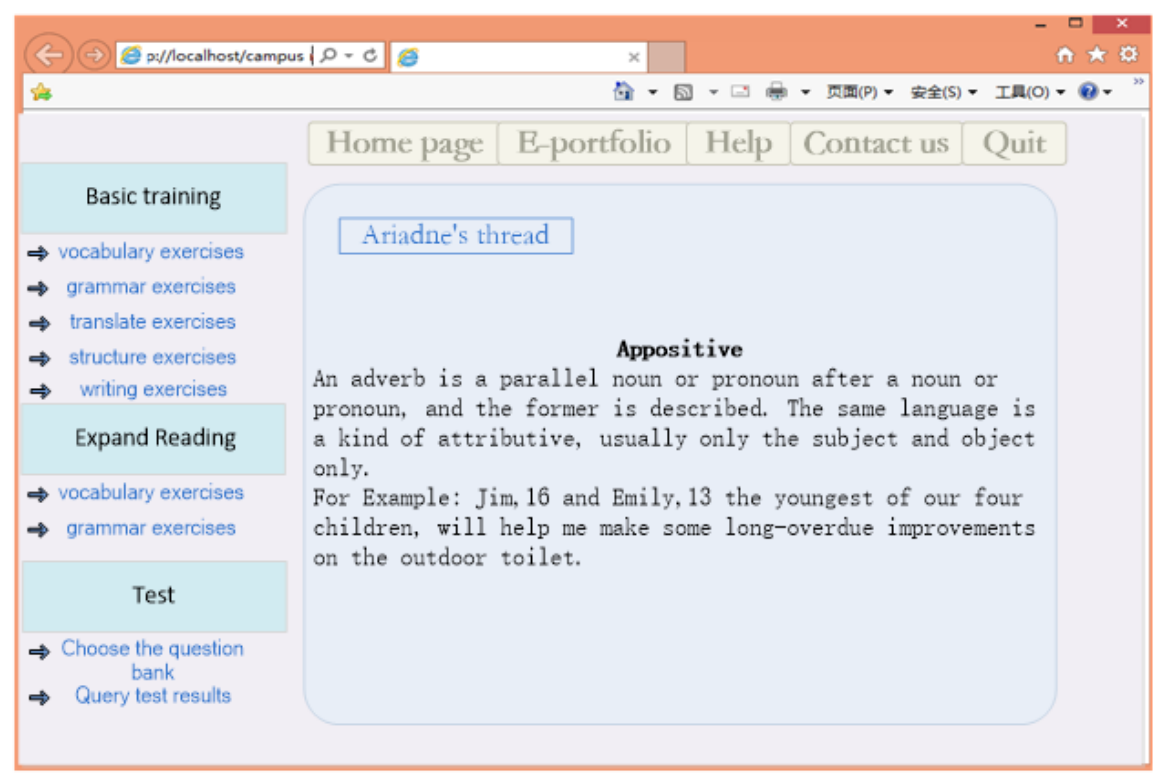

Fig. 5. The students learning the main interface appositive

\subsection{System test of personalized English teaching platform}

The test mainly observes whether the system achieves the design goal, including whether the functional requirements are realized, whether the business process is correct, whether the operating environment of the system is stable, and whether the system bug is controllable.

The main contents of the system test include functional test, performance test, and safety test. Functional test may try all interface operations as much as possible, and complete the function proofreading; the performance test mainly observes the impact of the system on CPU share and disk space occupancy. At the same time, the test ensures that the system cannot break down when the 200 users log in and read the data at the same time, with normal reaction speed. The system security mainly verifies the protection of user passwords and the guarantee of the system openness by the system, and also determines that the data can be saved effectively when the user exits the system.

According to the above requirements, the system tests are carried out one by one, and the test results should show that the system has reached the requirements for function, performance and safety, and complete the design of the personalized English teaching platform based on campus network. 


\section{Conclusions}

In order to improve the level of college English teaching and raise students' interest in English learning, this paper aims to design a personalized English teaching platform. The popularity of the campus networks in colleges and universities has laid a foundation for Web data interaction and storage pattern based on B/S framework, and the design of personalized English teaching platform is completed with computer technologies of VBSCRIPT and SQL database, after the detailed analysis of system requirements, and passes the system test. The system has the following advantages:

1. The platform is completely open, and the network teaching model fully embodies the student-oriented learning philosophy.

2. The function of the platform greatly facilitates the teaching management of teachers, who can give full play to the guiding role.

3. The platform subdivides the English knowledge into many sub-modules, and students can learn and test according to their English proficiency.

\section{Acknowledgement}

This paper is an outcome of "OBE Concept-based English Majors Cultivation Mode", a general subject/project of the $13^{\text {th }}$ Five-Year Plan of Education Sciences, Jilin Province (Grant No. GH170466).

\section{$7 \quad$ References}

[1] Antoine, H., Cédric B. (1992). Scripting windows: automatiser les tâches d'administration avec vbscript, wsh, wmi, adsi et les objets com. Palaios, 7(3), 277-293.

[2] Baylari, A., Montazer, G.A. (2009). Design a personalized e-learning system based on item response theory and artificial neural network approach. Expert Systems with Applications, 36(4), 8013-8021. https://doi.org/10.1016/j.eswa.2008.10.080

[3] Beckenstein, M. (2013). System requirements analysis: a management tool. IEEE Transactions on Engineering Management, 19(4), 124-128.

[4] Chen, Y.C. (2014). An empirical examination of factors affecting college students' proactive stickiness with a web-based English learning environment. Computers in Human Behavior, 31(31), 159-171. https://doi.org/10.1016/j.chb.2013.10.040

[5] Garrido, A., Onaindia, E. (2013). Assembling learning objects for personalized learning: an $\mathrm{Ai}$ planning perspective. IEEE Intelligent Systems, 28(2), 64-73. https://doi.org/10.1109/MIS.2011.36

[6] Hsu, M.H. (2008). A personalized English learning recommender system for ESL students. Expert Systems with Applications, 34(1), 683-688. https://doi.org/10.1016/ j.eswa.2006.10.004

[7] Ishihara, S., Kitamura, N., Atsumi, K., Itaya, T. (2002). Campus network in suzuka national college of technology: renewal of the network configuration in 2007. Research in Microbiology, 153(6), 361-368. 
[8] Kim, H.J., RD, C. (2012). A self-directed dynamic web-based learning environment: personalized learning framework. Epidemiology, 15(8), 3265-3275.

[9] Kuk, K., Jovanovic, D. (2013). Design and implementation of coaelearn modules for personalized game based-learning within computer architecture course. International Journal of Engineering Education, 29(3), 620-633.

[10] Mangkulo, H.A. (2004). Belajar sendiri aplikasi database menggunakan ado VB 6.0 DAN SQL server 2000. Geomorphology, 70(3-4), 257-278.

[11] Patel, S.D., Perera, A., Law, N., Mandumula, S. (2011). Requirements integration - system requirements analysis - 6.4. British Journal of Radiology, 84(1008), 240-2. https://doi.org/10.1259/bjr/42137038

[12] Tian, W. (2011). Construction of a teaching resources sharing platform based on campus network. Journal of Digital Information Management, 9(6), 261-265.

[13] Xiong, M., Shu, B.T., Li, P.K., Chen, C.H. (2003). A web-enhanced dynamic bom-based available-to-promise system. International Journal of Production Economics, 84(2), 133147. https://doi.org/10.1016/S0925-5273(02)00414-0

[14] Yao, C. (2017). A case study on the factors affecting Chinese adult students' English acquisition in a blended learning environment. International Journal of Continuing Engineering Education and Life-Long Learning, 27(1/2), 22. https://doi.org/10.1504/IJC EELL.2017.080993

[15] Yao, J.J., Yao, D., Givens, G. (2015). A browser-server-based tele-audiology system that supports multiple hearing test modalities. Telemedicine and e-Health, 21(9), 697-704. https://doi.org/10.1089/tmj.2014.0171

[16] Zou, Y.C. (2002). The roots and logical starting points of constructivist learning theory. Studies in Foreign Education, 61-71.

\section{Author}

Hongmei Wang received the B.A. degree in English from Beihua University, Jilin City, China, in 2001, the M.A degree in Foreign Linguistics and Applied Linguistics from Beihua University, Jilin City, China, in 2007. Since 2001, she has been on the faculty of Jilin Institute of Chemical Technology. Her research interests include applied linguistics and translation.

Article submitted 16 October 2017. Resubmitted 29 November 2017. Final acceptance 25 March 2018. Final version published as submitted by the author. 